\title{
The Message Conveyed By IFRS-Compliant Information: A South African Perspective
}

Pieter van der Zwan, North-West University, South Africa

Nico van der Merwe, North-West University, South Africa

\begin{abstract}
South African companies must prepare financial statements in accordance with International Financial Reporting Standards (IFRS) or other reporting standards modelled on IFRS. Literature suggests that the complexity of IFRS, which stems from detailed rules-based principles in these standards, may harm the ability of users of financial statements to understand financial information in a meaningful way. The primary objective of this study was to evaluate whether selected users and preparers of financial statements in South Africa interpret selected IFRScompliant information prepared in accordance with rules-based principles in the manner intended by the standard-setters. The results of the study, which are based on data gathered by administering a questionnaire that contained selected IFRS-compliant note disclosures to accounting practitioners, accountancy students, and non-accountants in business, suggest that the participants of the study did not understand such IFRS-compliant information as intended by the standard-setters. Additional disclosure, the adoption of a simplified accounting framework for Small and Medium-sized Entities (SMEs) and the use of an output-based continuing professional education (CPE) system are identified as areas that warrant further research to overcome the threats posed by rules-based principles in IFRS.
\end{abstract}

Keywords: International Financial Reporting Standards (IFRS); Rules-Based Principles; Complexity; Continuing Professional Education (CPE); Small and Medium-Sized Entities (SMEs)

\section{INTRODUCTION}

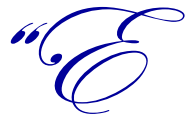

xpansion means complexity, and complexity decay”. The historian Cyril Northcote Parkinson described the development of organisational structures and regulations in this manner.

The preparation and presentation of financial statements are regulated by financial reporting standards, such as the International Financial Reporting Standards (IFRS). The 2010 Conceptual Framework (the Framework) describes that the objective of financial statements is to provide information about the economic resources, claims and changes in economic resources, and claims of an entity that is useful to existing and potential investors, lenders, and other creditors as the primary users of financial statements (IASB, 2010b). IFRS have developed into a complex financial reporting framework (FEI, 2007; Hitz, 2007:351; Pawsey, 2010; Tayebbi, 2008). It has been suggested that this complexity, which stems from many alternatives, bright-line tests, and exceptions contained in the relevant standards (IASB, 2008:11), may detract from the ability of the intended users of financial statements to understand and explain information contained in financial statements in a meaningful way (FEI, 2007). If users do not interpret information contained in financial statements correctly in the context of these complex rules, such financial statements fail to achieve their primary objective of addressing the information asymmetry between users and preparers of financial statements as the message conveyed to these users may not be the same as the message intended by the preparers of the financial statements or the standard-setters.

The concerns raised globally in respect of the complexity of IFRS pose the question whether this complexity may hold a similar threat to the message conveyed to users by financial statements in South Africa. The Companies Act (71/2008) (South Africa, 2008) requires companies that are listed on the Johannesburg Securities Exchange (JSE) to prepare financial statements in accordance with IFRS, while other companies are required to 
prepare their financial statements in accordance with IFRS or IFRS for Small and Medium-sized Entities (SMEs), depending on a number of criteria. A number of principles that are contained in IFRS have been simplified in IFRS for SMEs (IASB, 2009). Empirical evidence, however, suggests that preparers of financial statements are sceptical as to whether IFRS for SMEs provide sufficient relief from the burden of complying with IFRS (Van Wyk \& Rossouw, 2009:112-13). For the purposes of this article, IFRS and IFRS for SMEs are collectively referred to as 'IFRS-based reporting frameworks'. As all the financial reporting frameworks that companies in South Africa are required by law to use when preparing financial statements are based on IFRS, the central argument of this study is that the global concerns regarding the impact of complex rules or principles contained in IFRS on the message conveyed to users of such financial statements may also affect South African users.

As there appears to be little empirical research on the impact of the complexity of IFRS on the message conveyed to users of financial statements in South Africa, this study aims to make a contribution in bridging this gap in the literature. The main purpose of the study is to evaluate whether South African users and preparers of financial statements are also affected by the above concerns relating to the message conveyed by information prepared in accordance with the complex requirements of IFRS.

The literature review in the next section considers the origins of the complexities of IFRS. Based on this, the purpose and objectives of the study are defined and the methodology that was followed to achieve these objectives is described. The results of the study are then discussed. The article concludes by considering potential measures identified from the analysis of the results of the study that could be used to address the concerns raised as areas for further research. Lastly, limitations of the study are listed.

\section{THE ORIGIN OF THE COMPLEXITY OF IFRS}

The primary purpose of financial reporting is to reduce the information asymmetry between preparers and users of financial statements by providing relevant and timely information (Soderstrom \& Sun, 2007:676). As explained in the introduction, the objective of financial statements is to provide information to a fairly wide range of users that is useful for economic decision-making in their capacity as existing or potential investors, lenders, or creditors. Information contained in financial statements is useful if it has the qualitative characteristics of understandability, relevance, faithful representation and comparability (IASB, 2010a; IASB, 2010b). If financial statements do not present information that has these qualitative characteristics, they are likely to fail in their primary purpose.

The type of information that can be regarded as useful has been a burning issue during the course of the development of IFRS. Originally, the purpose of financial reporting has been to provide historical information to the owners of a business for legal and monitoring purposes. This function of financial reporting is referred to as the stewardship function (Whittington, 2008:144). There has, however, been a significant increase in financial reporting requirements that are aimed at providing generally useful information to investors and creditors about the current value of an entity, including the use of forward-looking estimates (Ball, 2006:13; IASB, 2010b; IASB, 2010c). It is submitted that financial statements still serve both purposes as it has to account to existing owners and lenders as to how their resources have been managed, but also provide information to prospective investors and lenders to evaluate whether to transact with or invest in an entity. A conflict exists between the nature of historical information used for monitoring purposes (stewardship) and information on the current value of an entity that is useful, in general, to investors and creditors (Whittington, 2008). This conflict arises from two contrasting characteristics that make information in financial statements useful to users; namely, reliability ${ }^{l}$ and relevance (Maines \& Wahlen, 2006).

\footnotetext{
${ }^{1}$ This term has been replaced by faithful representation in the Framework. From the Basis for Conclusions in the Framework it appears that the intention of the standard-setters with replacement of the word 'reliability' was not intended to downplay the importance of reliable information as paragraph BC3.24 states that "the term encompasses the main characteristics that the previous frameworks included as aspects of reliability". Other characteristics of the term 'reliability' have been incorporated in "verifiability" which is also a qualitative characteristic in the new Framework. The fact that 'reliable measurement' is still one of the recognition criteria for the elements of financial statements provides evidence of the importance of reliability in the Framework (IASB, 2010b). It is therefore submitted that financial statements cannot "faithfully represent" economic phenomena if the information contained in it does not have the characteristic of being reliable.
}

1042 Copyright by author(s) Creative Commons License CC-BY

2013 The Clute Institute 
The International Accounting Standards Board (IASB) has indicated that the reliability characteristic should not outweigh relevance (Ball, 2006:14). This has resulted in an increase in the number of instances where IFRS require entities to present relevant information, such as fair values that are determined using valuation models, even though these values may compromise reliability, to some extent, due to the estimation involved in their calculation. This tendency may indicate that the IASB has accepted a conceptual shift toward more relevant information, possibly at the expense of reliability, in the development of IFRS (Whittington, 2008:146). Barth (2006:272) is of the opinion that the reason for this trend is that amounts which reflect current economic conditions and up-to-date expectations of the future will be more useful in making decisions in the current economic environment than historical information. According to Whittington (2008:147), many critics, however, believe that the use of fair value accounting results in information that contains errors and bias as a result of the estimation and subjectivity involved in determining fair values that are reflected in financial statements. The increased requirement for the use of current information by IFRS has resulted in the concerns regarding reliability of IFRS-compliant information becoming more and more prevalent.

The reliability compromise arises from the need to make assumptions in order to determine the best measure of current values, which is not an absolute measure (Hitz, 2007; Pawsey, 2010). In order to address the concerns regarding this trade-off between relevance and reliability, these assumptions have been codified into principles, which are expanded on or clarified by more detailed rules and guidance, that users have to know, understand, and consider when interpreting information contained in financial statements (Hitz, 2007; Bennett, Bradbury \& Prangnell, 2006:189; Benston, Bromwich \& Wagenhofer, 2006:165; Nobes, 2004:10; IASB, 2010b). In this way, a relevant message is conveyed to users while they are aware of the reliability compromises necessary to prepare this information. Even though IFRS is often described as being based on 'principles' rather than 'rules', the need for guidance to ensure consistent interpretation of the principles has resulted in many authors holding the view that IFRS contain rules if required by the context as discussed above (Alexander \& Jermakowicz, 2006:134; Benston et al., 2006:183; Carmona \& Trombetta, 2008:456; Barth, 2008:1161; Bennett et al., 2006; Jamal \& Tan, 2009:4-5; Nobes, 2004). For the purposes of this article, a 'rules-based principle' refers to a principle, established by a financial reporting standard, that is expanded on by a set of detailed accounting rules that prescribe how this principle should be applied to comply with IFRS. In the context of the determination of current values, which appears to be one of the main areas where these detailed rules are used, this would mean that the accounting rules would provide detailed requirements as to the method and inputs used in determining the current value.

This codification of rules to expand on principles has increased the complexity of financial reporting (Tayebbi, 2008:4-5). As a result, some commentators are of the opinion that the requirements of modern financial reporting standards exceed the abilities of preparers and auditors to comply with it, thereby making IFRS-compliant information in the financial statements incomprehensible to the intended users (Epstein, 2007:6; Jermakowicz \& Gornik-Tomaszewski, 2006; Jermakowicz, Prather-Kinsey \& Wulf, 2007:153; McCarthy, 2004). Moreover, Fearnly and Hines (2007) are of the view that the growing perception in entities that are not subject to European Union (EU) Regulation is that IFRS is 'very complex and confusing'. These perceptions, in respect of the impact of detailed rules-based principles on the message conveyed to users by information in financial statements, raise the research question which is posed in the next section.

\section{PURPOSE OF THE STUDY AND RESEARCH OBJECTIVES}

The complexity of IFRS, which - according to the literature considered - has its origins in the use of rulesbased principles, may also affect the message conveyed to users of financial statements of a broad range of South African companies that are required to use IFRS-based reporting standards in preparing financial statements.

Based on this problem, the purpose of the study was to evaluate whether information in financial statements that is prepared in accordance with rules-based principles in the IFRS-based reporting standards used in South Africa achieve its primary purpose of conveying the message intended by the standard-setters to users. The primary objective of this study was to establish whether the message conveyed to present and future users and preparers of financial statements in South Africa, by selected IFRS-compliant information prepared in accordance with selected rules-based principles, was the correct message as intended by the standard-setters. 
The secondary objective of the study was to identify and explore areas for further research to address concerns raised by the results of the primary objective.

\section{RESEARCH METHODOLOGY}

The study was conducted by performing empirical research where data were collected by administering questionnaires to different groups of participants. The questionnaires contained extracts from financial statements of information prepared in accordance with rules-based principles in terms of IFRS. This section provides an overview of the content of the questionnaires as well as the nature of the participants involved in the study.

\section{Content of the Questionnaires}

The questionnaire provided to the participants contained three scenarios with IFRS-compliant note disclosures to reflect hypothetical information or transactions (hereafter referred to as 'fact patterns'). The participants were requested to indicate their interpretation of the message conveyed by the information in each of the fact patterns by choosing an interpretation provided by the researchers in the questionnaire or by describing their own interpretation if they did not agree with any of the interpretations provided.

The three fact patterns dealt with scenarios that would be treated similarly in terms of IFRS and IFRS for SMEs. The external validity of the questions was derived from the fact that they were based on the application of detailed requirements contained in the IFRS, which accountants and users should consult if they prepare financial statements in terms of IFRS or use such financial statements. Although the fact patterns in the questionnaire were developed from scratch, other authors have identified the broad topics covered as being significant and/or complex measurement issues that stem from the rules-based principles in IFRS (e.g. Jamal \& Tan, 2009:4; Nobes, 2004:1011; Nobes, 2006:241; Lantto \& Sahlström, 2009:345; Marden \& Brackney, 2009:36). In addition, the content of the three fact patterns were designed to address rules-based principles in respect of items that should be measured with reference to some form of current value for financial reporting purposes. This ensured that the fact patterns were linked to the origin of the complexities in IFRS as identified in the literature; namely, the rules-based principles relating to measurement, and were therefore relevant to the objectives of the study.

The validity and reliability was further ensured by administering a pilot questionnaire to a small group of participants to remove any ambiguities before it was administered to all participants. Time constraints may affect the reliability of the interpretation of the participants. In order to ensure that respondents had sufficient time to carefully consider each fact pattern and hence obtain reliable data, the number of fact patterns was limited to three and the questionnaires were administered toward the end of 2010 during training sessions or lectures where time was dedicated to the completion of the questionnaires. Given these measures put in place to ensure the validity and reliability of the questionnaire, an assumption was made that the participants' ability to choose the 'correct' interpretation $^{2}$ therefore primarily depended on their knowledge and comprehension of the underlying rules and principles in IFRS relating to the reporting of the selected information disclosed in the fact pattern. This research design links to the central argument of this article as the complexity of some rules-based principles in IFRS may impair the ability of users and preparers to comprehend information prepared in accordance with these rules and principles, which can ultimately manifest in less useful information in financial statements that does not convey the message intended by the standard-setters to the relevant users.

Under this common theme of rules-based principles, in respect of current values used in the measurement of items in financial statements, each fact pattern was specifically designed to consider the potential problem caused by the complexity of such rules-based principles from a different perspective.

\section{Fact Pattern 1}

Fact pattern 1, which dealt with the initial measurement of trade receivables at fair value, tested whether participants were aware of the principle contained in the relevant standards but also whether the participants

\footnotetext{
${ }^{2}$ For purposes of the interpretation of the results of this study, 'correct' means to interpret the information to mean exactly what it is supposed to mean in terms of the relevant financial reporting standard.
} 
interpreted information consistently where the requirements of the standards left room for interpretation. IAS 39 Financial instruments: Recognition and measurement requires that a receivable should be recognised at a discounted value at initial recognition unless the effect of discounting is immaterial. The standard does, however, not provide detailed guidance or rules to establish the rate to be used when discounting the amount receivable in the future or the method to determine whether the effect of discounting is immaterial or not. This fact pattern was therefore included into the study to be able to compare observations in respect of a slightly less rules-based principle to the stringent rules-based principles in the other two fact patterns.

\section{Fact Pattern 2}

Fact pattern 2 provided disclosures with respect to an equity-settled share-based payment transaction. It was included in the study to test whether the participants were aware of and knowledgeable about a more recent ${ }^{3}$ rules-based requirement that incorporates elements of fair value accounting.

\section{Fact Pattern 3}

Lastly, Fact pattern 3 prompted the participants to consider the meaning of the residual value of a building a value that commonly affects most financial statements of entities owning property. This fact pattern tested whether participants were aware of the extremely detailed requirements codifying the assumptions to be made in relation to forward-looking estimation involved in determining a residual value of a building in terms of IAS 16 Property, Plant and Equipment, which in turn affects the value of an entity's assets. The three fact patterns that were contained in the questionnaires administered to the participants appear in the Appendix to this article.

The materiality of the information in the fact patterns was considered to be an extraneous matter in deciding on the inclusion of the fact pattern into the study and interpretation of the results for purposes of achieving the research objectives, as the materiality of the impact of the rule or principle will depend on the circumstances and context in which it is applied. Similarly, the materiality of the impact of the differences in interpretation by the participants was not considered. This approach was justified by the view that the fact that IFRS contain detailed requirements, which the standard-setters must have put great thought into, would imply that the correct and accurate application of the finer details of rules and requirements could impact on the message conveyed to users by information.

Data from the questionnaires were captured in a spreadsheet and analysed using the statistical software package SPSS (SPSS, 2008) to ensure the use of accurate results and statistics to interpret the results.

\section{Participants}

The types of participants for the study were selected based on specific characteristics to achieve the objectives of the study. As the participants were selected on a convenience basis, as opposed to a statistical basis, the observations from the study could not be extrapolated to all users and preparers of financial statements in South Africa. Despite this limitation of the study, it is submitted that the results may nonetheless provide meaningful insight into the current situation in South Africa.

The first group of participants was accounting practitioners who are employed by small and medium-sized audit and accounting firms that do not have in-house technical IFRS units. Given the nature of their clients, these practitioners are actively involved in the preparation of IFRS-compliant financial information for their clients. The knowledge of the staff members and the audit partners at these firms is often the only available body of IFRS knowledge in the preparation of external financial statements. As these practitioners are therefore more likely to be directly affected by the complexity of rules-based principles in IFRS compared to larger firms who have in-house technical departments, they were included in the study. Due to their close interaction with the users of smaller entities' financial statements, the views of these preparers may also, to a large extent, reflect the views of users. The vast majority of these participants were partners or directors at the respective firms. The participants in this group had an average of 15.4 years of experience in the accountancy field.

${ }^{3}$ IFRS 2 Share-based Payment became effective for annual periods commencing on or after 1 January 2005. 
The second group of participants consisted of students studying towards a Masters in Business Administration (MBA) degree (hereafter referred to as the 'non-accountants'). These participants are employed in the business sector, often in leadership positions, and their companies often engage with entities in the capacity of investors, lenders or at least creditors (thus the users envisaged in the objective of financial statements in the Framework). They represent users who are assumed to be persons with reasonable knowledge of business, economic activities and accounting, and who study the information with reasonable diligence as intended by the Framework (IASB, 2010a; IASB, 2010b). None of them were, however, financial reporting specialists, although the MBA curriculum included some accountancy modules. These participants were included in the study as their views would be indicative as to whether persons who are not from a financial reporting specialist background - but who would deal with an entity as an existing or potential investor, lender, or creditor - would interpret IFRS-compliant information prepared in accordance with rules-based principles in the manner intended by the standard-setters.

The last group of participants consisted of accounting students who had been lectured on the topics covered by the fact patterns by the time the questionnaire was administered. The students included full-time final-year chartered accountancy students, as well as part-time final-year chartered accountancy students, from two South African Institute of Chartered Accountants (SAICA)-accredited universities. The part-time students were employed by one of the Big Four audit firms, as well as by the small and medium-sized auditing and accounting firms, where the accounting practitioners referred to above were involved. Given the different characteristics of full-time and part-time students, the results of the study were analysed separately for full-time and part-time students. These participants were included in the study as they will be the future preparers and users of financial statements. Moreover, the inclusion of students as participants allowed for a comparison of their more recently acquired detailed knowledge about the rules-based principles in IFRS with the knowledge of accounting practitioners in the firstmentioned group. The number of participants in each group is reflected in Table 1.

Table 1: Participants to the Study

\begin{tabular}{lcc}
\hline \multicolumn{1}{c}{ Group } & n & Percentage \\
\hline Accounting practitioners (excluding part-time students) & 35 & $15 \%$ \\
Part-time accountancy students (trainees) & 48 & $21 \%$ \\
Full-time accountancy students & 51 & $22 \%$ \\
Non-accountants (MBA students) & 97 & $42 \%$ \\
\cline { 2 - 3 } & & 231 \\
\hline
\end{tabular}

The response rate was $100 \%$ as all the questionnaires were administered and immediately collected in the time reserved for this purpose during training sessions and lectures. An insignificant number of questionnaires were unusable due to incompleteness.

\section{RESULTS AND DISCUSSION}

In order to consider whether the participants interpreted the information - in the fact patterns that was prepared in accordance with the rules-based principles - correctly, the data gathered from the questionnaires were analysed in aggregate. It was also disaggregated between the different groups of participants to obtain descriptive statistics and make observations, regarding the nature of participants who interpreted the information in the fact patterns, correctly. 


\section{Aggregated Results}

Table 2 summarises the aggregated results gathered from the participants on the message conveyed to them by the information in each of the three fact patterns.

Table 2: Interpretation of Fact Patterns by the Participants ${ }^{4}$

\begin{tabular}{|l|c|c|c|}
\hline & \multicolumn{3}{|c|}{ Percentage of Respondents } \\
\hline & Fact Pattern 1 & Fact Pattern 2 & Fact Pattern 3 \\
\hline Option 1 & $12 \%$ & $10 \%$ & $3 \%$ \\
\hline Option 2 & $17 \%$ & $6 \%$ & $24 \%$ \\
\hline Option 3 & $10 \%$ & $21 \%$ & $12 \%$ \\
\hline Option 4 & $29 \%$ & $5 \%$ & $21 \%$ \\
\hline Option 5 & $12 \%$ & $23 \%$ & $11 \%$ \\
\hline Option 6 & $2 \%$ & $12 \%$ & $1 \%$ \\
\hline Option 7 & $0 \%$ & $2 \%$ & $21 \%$ \\
\hline No answer & $17 \%$ & $22 \%$ & $\mathbf{1 0 0} \%$ \\
\hline Total & $\mathbf{1 0 0} \%$ & $\mathbf{1 0 0} \%$ & \\
\hline
\end{tabular}

The correct interpretation of the information in Fact pattern 1, in terms of the IFRS-based reporting frameworks, were options 2,3 and 4 . In total these interpretations were chosen by $56 \%$ of the participants. The consistency of the interpretations between these three options, however, differed substantially between the participants who provided an acceptable view. It is submitted that this dispersion of interpretations may be an indication that, in the absence of more detailed rules or guidance, users of financial statements are unlikely to interpret the IFRS-compliant information consistently. This result, which could have been expected, illustrates the reason why more detailed rules to guide the interpretation were introduced in other parts of IFRS, amongst others the aspects covered in the other two fact patterns.

The correct interpretation for the disclosure in Fact pattern 2 was provided to the participants in option 6. The information in this fact pattern, however, only conveyed this intended message to $12 \%$ of the participants, while the remaining $88 \%$ interpreted the information to mean something different. It is also noteworthy that Fact pattern 2, which dealt with a more recent development, was the least correctly interpreted by the participants of the study. The cause of this observation was further investigated in the next section to determine whether it could be attributed to a specific group of participants.

In respect of Fact pattern 3, option 5 was the correct interpretation. Only $21 \%$ of the participants interpreted this fact pattern correctly in the manner intended by the standard-setters.

The aggregated results - in particular those for Fact patterns 2 and 3 - provide evidence that the message conveyed to the participants by the selected IFRS-compliant disclosures prepared in accordance with the selected rules-based principles was not the message intended by the standard-setters. Even though this result cannot be extrapolated to a greater population due to the basis on which the participants were selected, it is submitted that it could be an indication that a similar problem may exist in the message conveyed by information prepared in accordance with other rules-based principles and also in the greater population of users of financial statements in South Africa.

It is interesting to note that the percentage of participants who interpreted Fact pattern 3 correctly was relatively low, if it is considered that an item such as a building would appear on most financial statements and that the participants would often be required to consider the issue addressed in this fact pattern. It is submitted that the relatively low percentage of correct interpretations may be attributable to the fact that the differences between the options available came down to wording and were quite technical in nature as a result of the very detailed

\footnotetext{
${ }^{4}$ Many instances were identified where participants answered some of the fact patterns, but not all of them. This may indicate that these participants attempted to answer the fact patterns to the best of their knowledge, but probably lacked the knowledge of the detailed rules-based principle to answer a particular fact pattern. The 'No answer' categories did therefore not all occur on the same questions.
} 
requirements of the definition of residual value in IAS 16 Property, Plant and Equipment. This low rate of correct interpretation illustrates the threat that detailed requirements in definitions or rules may pose to the message conveyed by information in financial statements. The low rate of correct interpretation of Fact pattern 2 may indicate the same concern regarding the rule-driven measurement requirements of IFRS 2 Share-based payment, which contain similar detailed requirements of assumptions to be incorporated into the amount of the expense in respect of the equity instruments awarded to employees.

A comparison of the results obtained from Fact pattern 1 to those of Fact patterns 2 and 3 show that rulesbased principles in accounting standards appear to be both desirable (to promote consistency in the message conveyed by information) and undesirable (as they add to complexity and cause users to interpret information in a way that is different than the intention of the standard-setters). The results obtained from these three fact patterns demonstrate the conundrum faced by the standard-setters who attempt to strike a balance between principles and rules to apply those principles in accounting standards. The possibility of more disclosure, with respect to areas where standards leave room for interpretation and simplification of rules-based principles in certain contexts, is considered later in this article as a possible way in which the concern regarding the message conveyed to users of financial statements can be addressed.

In the next section, the results were disaggregated in an attempt to gain further insight into the roots of these findings in order to be able to identify more areas for research relating to possible measures to address the concerns identified by the results in this section.

\section{Disaggregated Results}

The first disaggregated analysis performed was to determine whether the correctness of the message conveyed by the IFRS-compliant disclosures prepared in accordance with the relevant rules-based principles varied significantly between the various groups of participants. In order to establish whether differences in this regard existed, the relationship between the correct interpretation of the disclosures in the fact patterns and the various participant groups was cross-tabulated. The results of the cross tabulation are reported in Table 3.

Table 3: Cross Tabulations of Right/Wrong Answers to the IFRS Fact Patterns and Participant Groups

\begin{tabular}{|c|c|c|c|c|c|c|c|c|c|c|c|}
\hline \multirow{2}{*}{\multicolumn{2}{|c|}{ Participant Groups }} & \multicolumn{3}{|c|}{ Fact Pattern 1} & \multicolumn{3}{|c|}{ Fact Pattern 2} & \multicolumn{3}{|c|}{ Fact Pattern 3} & \multirow{2}{*}{$\begin{array}{c}\text { Average } \\
\text { Rank }\end{array}$} \\
\hline & & Wrong & Right & Rank & Wrong & Right & Rank & Wrong & Right & Rank & \\
\hline \multirow{2}{*}{$\begin{array}{l}\text { Accounting } \\
\text { practitioners }\end{array}$} & Count & 14 & 21 & & 34 & 1 & & 27 & 8 & & \\
\hline & $\%$ & 40.0 & 60.0 & 3 & 97.1 & 2.9 & 4 & 77.2 & 22.8 & 3 & 3.33 \\
\hline \multirow{2}{*}{$\begin{array}{l}\text { Part-time } \\
\text { accountancy } \\
\text { students }\end{array}$} & Count & 16 & 32 & & 35 & 13 & & 37 & 11 & & \\
\hline & $\%$ & 33.3 & 66.7 & 2 & 72.9 & 27.1 & 1 & 77.1 & 22.9 & 2 & 1.67 \\
\hline \multirow{2}{*}{$\begin{array}{l}\text { Full-time } \\
\text { accountancy } \\
\text { students }\end{array}$} & Count & 6 & 45 & & 41 & 10 & & 36 & 15 & & \\
\hline & $\%$ & 11.8 & 88.2 & 1 & 80.4 & 19.6 & 2 & 70.6 & 29.4 & 1 & 1.33 \\
\hline \multirow{2}{*}{ Non-accountants } & Count & 64 & 33 & & 94 & 3 & & 83 & 14 & & \\
\hline & $\%$ & 66.0 & 34.0 & 4 & 96.9 & 3.1 & 3 & 85.6 & 14.4 & 4 & 3.67 \\
\hline \multirow{2}{*}{ Total } & Count & 100 & 131 & & 204 & 27 & & 183 & 48 & & \\
\hline & $\%$ & 43.3 & 56.7 & & 88.3 & 11.7 & & 79.2 & 20.8 & & \\
\hline \multicolumn{2}{|c|}{$\begin{array}{l}\text { Chi square (if a random } \\
\text { sample was assumed) }\end{array}$} & \multicolumn{3}{|c|}{$\mathrm{p}<.0001$} & \multicolumn{3}{|c|}{$\mathrm{p}<.0001$} & \multicolumn{3}{|c|}{$\mathrm{p}=.179$} & \\
\hline \multicolumn{2}{|c|}{ Cramer's V } & \multicolumn{3}{|c|}{.432 (medium/large) } & \multicolumn{3}{|c|}{.320 (medium) } & \multicolumn{3}{|c|}{.146 (small) } & \\
\hline
\end{tabular}

The authors reported Chi square $p$ values (statistical significance) as part of the results of this cross tabulation for the sake of completeness. The results were, however, only interpreted based on the effect sizes ${ }^{5}$ of the association between the two variables as inferential statistics could not be used due to the fact that the participants

\footnotetext{
${ }^{5}$ Practical significance as denoted by Cramer's V, which takes into account the degrees of freedom for the tables with dimensions larger than two by two (Pallant, 2007:217). For the two by two tables the Cramer's V values equalled the phi coefficients.
} 
were not randomly selected. The following guidelines, as provided by Pallant (2007:217), were used for interpreting the strength of the effect sizes between the categorical variables:

- $\quad$ Small effect: $r=.10$

- $\quad$ Medium effect: $r=.30$

- Large effect: $r \geq .50$ (and also practically significant)

The rankings in Table 3 provide evidence that there was an observable difference in the extent of the correctness of the message conveyed by the disclosures in the fact patterns between the groups of participants. These rankings show that, on average, the accountancy students were ranked highest for all three fact patterns, indicating that they interpreted the IFRS-compliant disclosures in the fact patterns in the way intended by the IFRS standardsetters to a greater degree than the other groups of participants. In two of the three fact patterns, the part-time students interpreted the IFRS-compliant disclosures less correctly than the full-time students. In both of these instances, the correctness of their interpretations was closer to that of the accounting practitioners than to the correctness of the full-time students' interpretations.

The accounting practitioners ranked below the students for all the fact patterns. A noticeable exception to this observation was that the accounting practitioners were ranked below the non-accountants for fact pattern 2. As these rules-based principles are not noticeably more complicated than those applicable in the other two fact patterns, this discrepancy may raise concerns in respect of the continued professional education (CPE) system which should have informed the accounting practitioners' knowledge of more recent developments in rules-based principles.

The correctness of the interpretations of the non-accountants was generally ranked the lowest of all participants. The low percentage of correct interpretations of non-accountants, relative to the other groups of participants, provides evidence of a general lack of comprehension of the information prepared in accordance with the selected rules-based principles. This poses the question whether such requirements are successful in conveying the intended message to persons who are not financial reporting specialists but who may deal with an entity in their capacity of investor, lender, or creditor.

As the results in Table 3 indicated that there was a clear difference between the non-accountants and the other participants, the next step in the analysis was to explore differences between the other groups of participants, excluding the non-accountants (i.e., between those groups with a financial reporting specialist background). Table 3 already indicated that there were differences in the correctness of the interpretation of the fact patterns between these three groups of participants. In order to establish whether these differences were practically significant and whether the correctness of the interpretation of the IFRS-compliant disclosures was associated with the group that the participants formed part of, effect sizes (Cramer's V) were once again considered. Table 4 provides a comparison of effect sizes between full-time accountancy students, part-time accountancy students, and accounting practitioners for each of the three fact patterns.

Table 4: Cramer' V Compared between Full-Time Accountancy Students, Part-Time Accountancy Students and Accounting Practitioners

\begin{tabular}{|l|c|c|c|}
\hline $\begin{array}{c}\text { Association Between Correct/Incorrect } \\
\text { Interpretations And The Following Participant } \\
\text { Groups: }\end{array}$ & Fact Pattern 1 & Fact Pattern 2 & Fact Pattern 3 \\
\cline { 2 - 4 } & Cramer's V & Cramer's V & \multirow{2}{*}{ Cramer's V } \\
\hline All groups except for non-accountants & .273 & .248 & .073 \\
\hline Accounting practitioners and full-time students & .328 & .246 & .073 \\
\hline Accounting practitioners and part-time students & .069 & .319 & .001 \\
\hline Accounting practitioners and all students combined & .176 & .233 & .034 \\
\hline Part-time students and full-time students & .259 & .088 & .074 \\
\hline
\end{tabular}

The values reported in Table 4 indicate that in respect of Fact pattern 1, there were medium effect sizes in the association between correct/incorrect interpretations and the full-time accountancy students compared to accounting practitioners, and also between correct/incorrect interpretations and the full-time accountancy students compared to part-time accountancy students. This suggests that it was moderately less likely that an accounting 
practitioner or part-time accountancy student would interpret the message conveyed by the IFRS-compliant disclosures prepared in accordance with rules-based principles in Fact pattern 1 in the manner intended by the standard-setters compared to a full-time accountancy student.

Table 4 further shows that the effect size of the association between the correctness of the interpretation of Fact pattern 2 and the classification of accountancy student (full-time or part-time) was small. The type of accountancy student therefore had a small impact on the correctness of the interpretation of this fact pattern. When considering the accounting practitioners and both groups of students separately or combined (.246, .319, and .233), the effect sizes were medium or leaned toward a medium effect.

The observations in respect of the first two fact patterns indicate that accounting practitioners generally interpreted the fact patterns less correctly than accounting students - in particular, fact pattern two that dealt with a more recently introduced rules-based principle. This raises the same concern identified earlier regarding the effectiveness of the CPE system in updating and maintenance of the accounting practitioners' knowledge of rulesbased principles. This area is further explored later.

Lastly, the comparison in Table 4 shows that the effect size of the association between the correctness of the interpretation of Fact pattern 3 and classification as an accounting practitioner or part-time student was similarly to Fact pattern 1 - small. However, contrary to observation of Fact pattern 1, all the effect sizes for Fact pattern 3 were small, indicating that the nature of the participant did not have the same impact on the correctness of the interpretation of this fact pattern, as it did for the other two. This observation would suggest that all participants experienced the same problem in interpreting information prepared in accordance with a very detailed and technically worded rules-based principle. An area to address this concern in the context of small and medium sized entities is considered later in this article.

\section{Concluding Thoughts on the Results}

In 1942 the U.S. Securities Exchange Commission (SEC) aptly described the purpose of financial statements as follows: 'The basic question [is] whether the financial statements performed the function of enlightenment, which is their only reason for existence' (Tweedie, 1983). The analysis of the results in this section suggest that the IFRS-compliant disclosures, which were based on the application of selected rules-based principles in the relevant IFRS-based reporting frameworks, did not provide the information intended by the standard-setters to the participants of the study, indicating that these disclosures failed in their primary purpose.

Despite the challenges posed by the complexity of such IFRS rules-based principles, which appear to distort the message conveyed to users and preparers of financial statements in South Africa, IFRS-based reporting frameworks, nevertheless, have benefits that have resulted in their use, spreading rapidly across the globe (Pawsey, 2010:1-2). Some commentators believe that the IASB has been successful in developing a complete set of standards that - if adhered to - provides relevant information to users of financial statements (Ball, 2006; Soderstrom \& Sun, 2007:695). In addition to the benefits provided to the users of financial statements, Epstein (2007:10) is of the view that compliance with high-quality universally relevant accounting standards, such as IFRS, will contribute to improved management practices of businesses, which will provide the foundation for optimal capital allocation and economic growth in the long run.

Given these benefits, it would be in the best interest of users and preparers of financial statements in South Africa to overcome the challenges arising from the application of rules-based principles to share in these benefits presented by IFRS where possible. The next section briefly identifies and considers three areas for further research that may contribute to addressing the concerns raised by the results reported above. 


\section{POSSIBLE AREAS IDENTIFIED TO ADDRESS CONCERNS}

\section{Striking a Balance between the Need for Disclosure and Rules-Based Principles}

The results reported in the previous section in respect of Fact patterns 2 and 3 indicate that complex and detailed technical rules that guide the application of principles resulted in the participants not interpreting the disclosures in the manner intended by the standard-setters. However, principles with less rules or guidance, such as those in Fact pattern 1, resulted in more correct interpretation of the information, which may indicate that this type of principle achieves its purpose better than a complex detailed rules-based principle. Yet these interpretations within those allowed by the relevant standards were inconsistent between participants. This illustrates the problem caused by the use of principles with less rules and guidance to dictate the application of the principle.

The authors are of the view that the inconsistent interpretations could have been reduced if more information on certain key assumptions, such as the discount rate used or whether the receivables were discounted or not, was disclosed to participants in the particular disclosure provided to them. It is submitted that such disclosure requirements should be more specific to areas where the standards leave room for interpretation than the general requirements of the IFRS standard on presentation of financial statements, which contain overriding requirements to disclose judgements and the effect of estimation uncertainties (IASB, 2010c). Additional disclosure may lessen the burden on users of financial statements to know large volumes of detailed rules.

Additional disclosures, in itself, may, however, not fully address the problem. Firstly, the requirements for these disclosures could add to an already onerous list of same that preparers should adhere to, even though it would merely require preparers to disclose aspects of a transaction that they had to consider in any case. Although some evidence exists about the incremental information content of additional disclosures (for example, Lang \& Lundholm, 1996; Hoskin, Hughes \& Ricks, 1986:27), there appears to be quite a substantial amount of literature that supports a view that recognised information has a greater impact on an entity's value and that disclosed information is regarded as less reliable than recognised information (Aboody, 1996:30; Ahmed, Kilic \& Lobo, 2006; Barth, Clinch \& Shibano, 2003; Davis-Friday, Liu \& Mittelstaedt, 2004; Espahbodi, Espahbodi, Rezaee \& Tehranian, 2002:366). This may cause debate as to whether additional disclosure in areas where standards leave room for interpretation would add sufficient value to users to justify such a disclosure requirement.

Based on the results of the study and the views expressed in the literature, it is suggested that further research into the situations in which additional disclosure could be used, as opposed to using more detailed rulesbased principles, would be warranted, both in the context of the development of IFRS globally as well as the development of reporting standards in South Africa.

\section{Need for a Simplified Reporting Framework for Certain Users}

As the results of Fact patterns 2 and 3, that dealt with detailed and technically worded rules-based principles, suggested a lack of knowledge of these requirements contained in the reporting standards, in particular in the context of practitioners serving small and medium-sized entities (SMEs), as well as users without a specialist financial reporting background, the need for a simplified reporting framework that contains less detailed rules-based principles than IFRS in South Africa is apparent. As the rules-based principles included in the fact patterns are identical in IFRS and IFRS for SMEs, a similar concern appears to exist in respect of the use of such rules-based principles in IFRS for SMEs. This result is supported by the views of commentators, both national and international, who are of the opinion that substantial portions of IFRS for SMEs (which were developed for entities who typically employ about 50 people) are still too onerous and complex, especially for the needs of so-called "micro-entities" (Stainbank, 2010:57; Schiebel, 2008:1; Van Wyk \& Rossouw, 2009; EAAFRSC, 2004:20; SAICA, 2007; Neag, Maşca \& Pãşcan, 2009:35-36).

The need for such a framework for smaller entities is acknowledged globally (Jermakowicz \& Epstein, 2010:72). Literature in this area suggests that such a reporting framework is required for SMEs where the users of financial statements for SMEs are not regarded as "professional users" (experts) and these users normally do not understand the technical information required by IFRS. This audience may require less detailed and technical rules- 
based principles in such a reporting framework (Larson \& Street, 2004:115; Maingot \& Zeghal, 2006; Van Wyk \& Rossouw, 2009; Stainbank, 2010:66).

In response to calls for such a simplified framework, the Accounting Practices Board (APB) of South Africa published an exposure draft of a third-tier framework - called the Financial Reporting Framework for NonPublic Entities (which is also referred to as Micro-GAAP) - that was intended to provide a cost-effective process to create reliable and meaningful financial reports for smaller businesses in South Africa (SAICA, 2010a; SAICA, 2010b). The future of the Micro-GAAP framework, however, appears to be uncertain given concerns that the proposed framework was unlikely to achieve its objectives as it was not significantly simpler than IFRS for SMEs (APB, 2010; APC, 2010) and the doubts over the continuing existence of the APB (SAICA, 2012).

It is submitted that the results of this study, which were based on the knowledge of the requirements of rules-based principles, as opposed to perceptions and preferences in previous studies, confirm the need for such a framework in South Africa. The results may further indicate that the role of rules-based principles in this framework must be carefully considered as too many rules-based principles distort the message conveyed to users (as illustrated by the results of Fact patterns 2 and 3) while too few may render financial statements incomparable. It is suggested that further research should be performed on the scope of such a reporting framework as well as the nature of the requirements to be contained in it.

\section{Reflection on the Continued Professional Education (CPE) System}

Lastly, the fact that the results across the three fact patterns indicate that the accountancy students tended to generally interpret the IFRS-compliant disclosures, prepared in accordance with rules-based principles, more correctly than the accounting practitioners may raise questions as to the effectiveness of the CPE system (Epstein, 2007:10; Carmona \& Trombetta, 2008:455) that should maintain practitioners' knowledge of rules-based principles contained in IFRS-based reporting frameworks and also inform them about new developments (Friedman, Davis \& Phillips, 2000; Wessels, 2005:57). The findings in respect of Fact pattern 2, where both groups of students significantly outperformed the accounting practitioners, are especially important in this regard as this fact pattern dealt with a more recent IFRS development. It is imperative that CPE achieves its objectives of maintaining and updating knowledge in the challenging environment of rapidly changing financial reporting standards (Albrecht \& Sack, 2000; Rothwell \& Herbert, 2007:136). Given the limited information in the results of the study in this regard, the only contribution that these results could make in respect of CPE would be to suggest that the correctness of the interpretations of the students, who had been assessed in terms of an output-based method in their examinations at their respective universities, compared to those of the practitioners who have been subject to a time-driven inputbased CPE system used by professional bodies in South Africa (SAICA, 2008; SAIPA, 2011), may indicate that in respect of disciplines that contain detailed rules-based principles, an output-based assessment method may be preferable if CPE is to achieve its objective. This approach to CPE has been suggested by other professional bodies such as IFAC (2008:87-88). It is therefore suggested that the results of this study indicate a need for further research into the role and use of output-based CPE in respect of IFRS knowledge for accountants in South Africa.

\section{LIMITATIONS OF THE STUDY}

The results and areas for further research should be viewed in the context of the limitations of the study, which are briefly highlighted in this section.

Firstly, the participants in the study were not selected on a random basis, but rather on a convenience basis that enabled the authors to achieve the research objectives. The results obtained could therefore not be extrapolated to the whole population of present and future users and preparers of IFRS financial statements in South Africa, although the discussion of these results could provide meaningful insight into the position in South Africa.

Secondly, the findings in respect of the rules-based principles in IFRS were based on three fact patterns dealing with relevant areas identified from the literature. The use of different fact patterns may produce different results. In addition, the materiality of the impact of the specific rules-based principles was not considered as this would depend on the context in which the information appears, which was not available in the fact patterns. 
Thirdly, the results of the study do not provide views on the message conveyed to users by financial statements prepared in terms of an IFRS-based reporting framework as a whole, but merely on information prepared in accordance with rules-based principles that is contained in these financial statements. The authors' definition of the term 'rules-based principle' was based on views expressed in the literature. It is acknowledged that other persons may define this term in a different manner or that some commentators may hold the view that IFRS is solely principles-based and that preparers should exercise their judgement in a way that will provide the most useful information.

\section{CONCLUSION}

The results of the study reported in this article show that the message conveyed to South African users by information prepared in accordance with rules-based principles contained in IFRS is often distorted from the message intended by the standard-setters. As the use of IFRS-based reporting frameworks results in financial statements that provide high-quality information to users, measures to overcome this must be considered. This article contributed to the development of such measures by suggesting a number of areas for further research.

In conclusion, the results of this study uncovered a number of thought-provoking issues regarding the correctness of the message conveyed to users by IFRS-compliant information in the South African context, the role of rules-based principles in financial reporting standards and perhaps also the audience that financial statements in South Africa should cater to. If these issues are addressed sufficiently, it may play a role in preventing the complexities of IFRS from leading to its decay in South Africa.

\section{AUTHOR INFORMATION}

Pieter van der Zwan is an associate professor and the Taxation program leader at the North-West University in South Africa. $\mathrm{He}$ is a Chartered Accountant and holds the $\mathrm{CA}(\mathrm{SA})$ designation. E-mail: pieter.vanderzwan@nwu.ac.za

Nico van der Merwe is an associate professor and the Chartered Accountancy Training program leader at the Potchefstroom campus of the North-West University in South Africa. He is a Chartered Accountant and holds the CA(SA) designation. E-mail: Nico.Vandermerwe@nwu.ac.za (Corresponding author)

\section{REFERENCES}

1. Aboody, D. (1996). Recognition versus disclosure in the oil and gas industry. Journal of Accounting Research, 34:21-32.

2. Accounting Practices Board. (2010). Minutes of the meeting of the Accounting Practices Board held on 26 August 2010 from 09h00 - $13 \mathrm{~h} 00$ at Ndhlovu Room, SAICA. Retrieved from: https://www.saica.co.za/Portals/0/document/3\%20December\%202010/APB\%20minutes\%20for\%20the\%2 0meeting\%20held\%20on\%2026\%20August\%202010.pdf

3. Accounting Practices Committee. (2010). Minutes of the meeting of the Accounting Practices Committee held on 29 September 2010 at $13 \mathrm{~h} 00-17 \mathrm{~h} 00$ at Ndhlovu Room, Bruma. Retrieved from: https://www.saica.co.za/Portals/0/document/3\%20December\%202010/Attachment\%204\%20\%20APC\%20minutes\%20of\%2029\%20September\%202010.pdf

4. Ahmed, A.S., Kilic, E. \& Lobo, G.J. (2006). Does recognition versus disclosure matter? Evidence from value-relevance of banks' recognized and disclosed derivative financial instruments. Accounting Review, 81(3):567-588.

5. Albrecht, W.S. \& Sack, R.J. (2000). Accounting education: charting the course through a perilous future. Accounting Education Series, 16. Sarasota: American Accounting Association.

6. Alexander, D. \& Jermakowicz, E. (2006). A true and fair view of the principles/rules debate. Abacus, 42(2):132-164.

7. $\quad$ APB. See Accounting Practices Board.

8. APC. See Accounting Practices Committee. 
9. Ball, R. (2006). International Financial Reporting Standards (IFRS): pros and cons for investors. Accounting and Business Research, 36(Special Issue):5-27.

10. Barth, M.E. (2006). Including estimates of the future in today's financial statements. Accounting Horizons, 20(3):271-285.

11. Barth, M.E. (2008). Global financial reporting: Implications for U.S. academics. The Accounting Review, 83(5):1159-1179.

12. Barth, M.E., Clinch, G. \& Shibano, T. (2003). Market effects of recognition and disclosure. Journal of Accounting Research, 41(4):581-609.

13. Bennett, B., Bradbury, M. \& Prangnell, H. (2006). Rules, principles and judgments in accounting standards. Abacus, 42(2):189-204.

14. Benston, G.J., Bromwich, M. \& Wagenhofer, A. (2006). Principles- versus rules-based accounting standards: the FASB's standard setting strategy. Abacus, 42(2):165-188.

15. Carmona, S. \& Trombetta, M. (2008). On the global acceptance of IAS/IFRS accounting standards: The logic and implications of the principles-based system. Journal of Accounting and Public Policy, 27:455461.

16. Davis-Friday, P.Y., Liu, C. \& Mittelstaedt, H.F. (2004). Recognition and disclosure reliability: Evidence from SFAS no. 106. Contemporary Accounting Research, 21(2):399-429.

17. EAAFRSC. See European Accounting Association's Financial Reporting Standards Committee.

18. Epstein, B.J. (2007). Information overload can threaten sound decision-making. The CPA Journal, 77(6):910 .

19. Espahbodi, H., Espahbodi, P., Rezaee, Z. \& Tehranian, H. (2002). Stock price reaction and value relevance of recognition versus disclosure: the case of stock-based compensation. Journal of Accounting and Economics, 33:343-373.

20. European Accounting Association's Financial Reporting Standards Committee. (2004). Comment letter: SME standards. Retrieved from: http://www.accademiaaidea.it/downloads/Ias/c16.pdf

21. Fearnly, S. \& Hines, T. (2007). How IFRS has destabilised financial reporting for UK non-listed entities. Journal of Financial Regulation and Compliance, 15(4):394-408.

22. FEI. See Financial Executives International.

23. Financial Executives International. (2007). FEI's recommendations to address complexity in financial reporting. Retrieved from: http://www.financialexecutives.org/eweb/upload/FEI/4\%20Point\%20Plan.pdf

24. Friedman, A., Davis, K. \& Phillips, M. (2000). Continuing Professional Development in the UK: policies and programs. Bristol: PARN.

25. Hitz, J. (2007). The decision usefulness of fair value accounting - a theoretical perspective. European Accounting Review, 16(2):323-362.

26. Hoskin, R.E., Hughes, J.S. \& Ricks, W.E. (1986). Evidence on the incremental information content of additional firm disclosures made concurrently with earnings. Journal of Accounting Research, 24:1-32.

27. IASB. See International Accounting Standards Board.

28. IFAC. See International Federation of Accountants.

29. International Accounting Standards Board. (2008). Discussion Paper: reducing complexity in reporting financial instruments. London: IFRS Foundation.

30. International Accounting Standards Board. (2009). International Financial Reporting Standards for Small and Medium-sized Entities. London: IFRS Foundation.

31. International Accounting Standards Board. (2010a). Framework for the preparation and presentation of financial statements. London: IFRS Foundation.

32. International Accounting Standards Board. (2010b). The conceptual framework for financial reporting. London: IFRS Foundation.

33. International Accounting Standards Board. (2010c). IAS 1 Presentation of financial statements. London: IFRS Foundation.

34. International Federation of Accountants. (2008). Information paper: approaches to Continuing Professional Development (CPD) measurement. New York: IFAC.

35. Jamal, K. \& Tan, H. (2009). Effect of principles-based versus rules-based standards and auditor type on financial managers' reporting judgments. Retrieved from:

http://www.rotman.utoronto.ca/accounting/Jamal.doc 
36. Jermakowicz, E.K. \& Epstein, B.J. (2010). IFRS for SMEs - An option for U.S. private entities? Review of Business, 30(2):72-79.

37. Jermakowicz, E.K. \& Gornik-Tomaszewski, S. (2006). Implementing IFRS from the perspective of EU publicly traded companies. Journal of International Accounting, Auditing and Taxation, 15:170-196.

38. Jermakowicz, E. K., Prather-Kinsey, J. \& Wulf, I. (2007). The value relevance of accounting income reported by DAX-30 German companies. Journal of International Financial Management and Accountancy, 18(3):151-191.

39. Lang, M.H. \& Lundholm, R.J. (1996). Corporate disclosure policy and analyst behavior. The Accounting Review, 71(4):467-492.

40. Lantto, A. \& Sahlström, P. (2009). Impact of International Financial Reporting Standard adoption on key financial ratios. Accounting and Finance, 49:341-361.

41. Larson, R.K. \& Street, D.L. (2004). Convergence with IFRS in an expanding Europe: progress and obstacles identified by large accounting firms' survey. Journal of International Accounting, Auditing and Taxation, 13:89-119.

42. Maines, L.A. \& Wahlen, J.M. (2006). The nature of accounting information reliability: Inferences from archival and experimental research. Accounting Horizons, 20(4):399-425.

43. Maingot, M. \& Zeghal, D. (2006). Financial reporting of small business entities in Canada. Journal of Small Business Management, 44(4):513-530.

44. Marden, R.E. \& Brackney, K.S. (2009). Audit risks and IFRS: does increased flexibility increase audit risk? The CPA Journal, 79(6):32-36.

45. McCarthy, P.D. (2004). Unnecessary complexity in accounting principles. The CPA Journal, 74(3):18-19.

46. Neag, R., Maşca, E. \& Pãşcan, I. (2009). Actual aspects regarding the IFRS for SME - Opinions, debates and future developments. Annales Universitatis Apulensis Series Oeconomica, 11(1):32-42.

47. Nobes, C. (2004). Rules-based standards and the lack of principles in accounting. Retrieved from: http://www.econ.upf.edu/docs/seminars/nobes.pdf

48. Nobes, C. (2006). The survival of international differences under IFRS: towards a research agenda. Accounting and Business Research, 36(3):233-245.

49. Pallant, J. (2007). SPSS survival manual. 3rd Edition. Berkshire: McGraw-Hill Open University Press.

50. Pawsey, N. (2010). Australian preparer perceptions towards the quality and complexity of IFRS. In: Proceedings of the Sixth Asia Pacific Interdisciplinary Research in Accounting Conference, Sydney, Australia, 12-13 July 2010.

51. Rothwell, A. \& Herbert, I. (2007). Accounting professionals and CPD: attitudes and engagement - some survey evidence. Research in Post-Compulsory Education, 12(1):121-138.

52. SAICA. See South African Institute of Chartered Accountants.

53. SAIPA. See South African Institute of Professional Accountants.

54. Schiebel, A. (2008). Is there a solid empirical foundation for the IASB's draft IFRS for SMEs? Retrieved from: http://papers.ssrn.com/sol3/papers.cfm?abstract_id=994684

55. Soderstrom, N.S. \& Sun, J. (2007). IFRS adoption and accounting quality: a review. European Accounting Review, 16(4):675-702.

56. South Africa. (2008). Companies Act 71 of 2008. Pretoria: Government Printer.

57. South African Institute of Chartered Accountants. (2007). Submission to IASB: Exposure draft on international financial reporting standard for small and medium-sized entities. Retrieved from: http://www.saica.co.za/Default.aspx?tabid=772\&def

58. South African Institute of Chartered Accountants. (2008). Continuing Professional Development (CPD) policy. Retrieved from: https://www.saica.co.za/Portals/0/documents/cpd_policy _\%20with\%20verification\%20november_2008.pdf

59. South African Institute of Chartered Accountants. (2010a). Overwhelming support for new accounting standards framework. Communique, May.

60. South African Institute of Chartered Accountants. (2010b). Exposure Draft 285: financial reporting framework for non-public entities. Kengray: SAICA.

61. South African Institute of Professional Accountants. (2011). CPD Requirements. Retrieved from: http://www.saipa.co.za/page/517/cpd-requirements 
62. South African Institute of Chartered Accountants. (2012). Joint announcement by the Accounting Practices Board (APB) and the Financial Reporting Standards Council (FRSC) regarding SA GAAP. Retrieved from: https://www.saica.co.za/Portals/0/Technical/Future\%20of\%20SA\%20GAAP.pdf?Reference_ID=18105214

63. SPSS for Windows, Rel. 17.0.0. (2008). Chicago: SPSS Inc.

64. Stainbank, L.J. (2010). An examination of the due process in South Africa which led to the adoption of the draft International Financial Reporting Standard for Small and Medium-sized Entities. Meditari Accountancy Research, 18(2):57-74.

65. Tayebbi, A. (2008). Discussion paper: complexity in financial reporting: just the way it is? ACCA.

66. Tweedie, D. (1983). True and Fair Rules. The Accountant's Magazine, 87(929):424-449.

67. Van Wyk, H.A. \& Rossouw, J. (2009). IFRS for SMEs in South Africa: a giant leap for accounting, but too big for smaller entities in general. Meditari Accountancy Research, 17(1):99-116.

68. Wessels, S.B. (2005). The deterrents to CPE effectiveness in the accounting profession: a factor analytic study. Journal of Business and Economics Research, 3(6):57-66.

69. Whittington, G. (2008). Fair value and the IASB/FASB conceptual framework project: an alternative view. Abacus, 44(2):139-168. 


\section{APPENDIX: IFRS FACT PATTERNS (QUESTIONNAIRE)}

Please provide your interpretation of each of the three fact patterns below. Please choose only the one option that best describes your understanding of the scenario.

\section{Fact Pattern 1}

Extract From the Financial Statements

\section{Accounting Policy for Loans and Receivables}

Loans and receivables are recognised initially at fair value plus any directly attributable transaction costs. Subsequent to initial recognition loans and receivables are measured at amortised cost using the effective interest method, less any impairment losses. The fair value of trade and other receivables is estimated as the present value of future cash flows, discounted at the market rate of interest. Receivables are measured at face value, if the impact of discounting is not material.

\section{Extract from the Statement of Financial Position (Balance Sheet) as at 31 December 2010}

$\begin{array}{lll}\text { Receivables } & \text { Note } 1 & \text { R95 } 000\end{array}$

Note 1:

This receivable arose on the sale of goods on 31 December 2010. This transaction will be settled on 31 March 2011.

What does the receivable amount on the face of the balance sheet tell you?

1. The sales price of the transaction was R95 000 that will be received on 31 March 2011 as receivables always reflect the actual amount to be received.

2. The goods were sold for an amount exceeding R95 000. The present value of the sales price of the goods discounted at the prime interest rate for a 3 month period from 31 December 2010 to 31 March 2011 equals R95 000.

3. The goods were sold for an amount exceeding R95 000. The present value of the sales price of the goods discounted at a rate other than the prime interest rate for a 3 month period from 31 December 2010 to 31 March 2011 equals R95 000.

4. The receivable was recorded at its face value of R95 000 as the impact of discounting is immaterial for the period of 3 months until settlement.

5. The goods were sold for R95 000. The reporting entity will charge interest at the prime or another market related interest rate from 31 December 2010 to 31 March 2011.

6. Something other than the above - please specify: 


\section{Fact Pattern 2}

\section{Extract From the Financial Statements}

\section{Accounting Policy for Equity-Settled Share-Based Payment Transactions}

The grant date fair value of share-based payment awards granted to employees is recognised as an employee expense, with a corresponding increase in equity, over the period that the employees unconditionally become entitled to the awards. The amount recognised as an expense is adjusted to reflect the number of awards for which the related service and non-market vesting conditions are expected to be met, such that the amount ultimately recognised as an expense is based on the number of awards that do meet the related service and non-market performance conditions at the vesting date.

\section{Extract from the Statement of Comprehensive Income (Income Statement)}

$\begin{array}{lll}\text { Equity-settled share-based payment expense } & \text { Note } 2 & \text { R50 } 000\end{array}$

Note 2:

At the beginning of the financial year the entity established a share compensation programme that entitles each staff member to shares in the entity. Employees only qualify for the shares if they are employed by the entity for a period of 3 years and the market value of the entity's shares exceed R10 per share by the end of the three year period. At the end of the financial year it was expected that all the employees will remain in the employment of the entity for the full three year period and that the share price target will be achieved.

What does the equity-settled share-based payment amount in the Statement of Comprehensive Income tell you?

1. The reporting entity incurred a cost of R50 000 to buy shares to award to its employees in terms of the scheme.

2. The reporting entity will incur a cost of R150 000 to buy shares to award to its employees in terms of the scheme over the three year period.

3. The total market value of the shares awarded to the employees is R50 000.

4. The total market value of the shares awarded to employees is R150 000.

5. The value of the shares awarded to employees (taking into account the probability that the share price target will not be met) on the assumption that all employees will remain with the entity for three years was R50 000 at the beginning of the year.

6. The value of the shares awarded to employees (taking into account the probability that the share price target will not be met) on the assumption that all employees will remain with the entity for three years was R150 000 at the beginning of the year.

7. Something other than the above - please specify: 


\section{Fact Pattern 3}

\section{Extract From the Financial Statements}

\section{Accounting Policy for Property, Plant and Equipment}

Items of property, plant and equipment are measured at cost less accumulated depreciation and accumulated impairment losses. Depreciation is calculated based on the depreciable amount, which is the cost of an asset, or other amount substituted for cost, less its residual value. Depreciation methods, useful lives and residual values are reviewed at each financial year-end and adjusted if appropriate.

\section{Extract from the Statement of Financial Position (Balance Sheet):}

Buildings $\quad$ Note 31000000

Note 3:

\section{Buildings}

Opening carrying amount

Movements during the year:

Depreciation

Carrying amount at the end of the year

R1 000000

No depreciation was provided for on the building during the current financial year, as its residual value was equal to its carrying amount.

What does the information in note 3 tell you?

1. The building is not being used by the entity at the moment (i.e. it is temporarily idle), therefore it was not depreciated.

2. It is the entity's intention to sell the building, therefore it was not depreciated and it is shown at fair value (residual value).

3. The current market value of the building is R1 000000 if it was to be sold in its current condition on the reporting date, even though it is still the reporting entity's intention to use the building.

4. The market value of the building is likely to be R1 000000 (taking into account expected inflation) when it will one day be sold, if it is assumed that it will be sold in its current condition, even though it is still the reporting entity's intention to use the building.

5. The market value of the building on the reporting date is likely to be R1 000000 , if this building was to be sold on the reporting date in the condition that it is expected to be at the end of its useful life, even though it is still the reporting entity's intention to use the building.

6. The building's replacement value (i.e. the purchase price of a new building) is R1 000000 on the reporting date.

7. Something other than the above - please specify: 
NOTES 